\title{
Investigation of the Effect of the Dyeing Method on the Dyeing Properties of Wool Fabrics Dyed with Natural Dyes Extracted from Vaccinium Corymbosum L.
}

\author{
Mehmet KILINC $^{1}$, Dilara KOCAK ${ }^{2}$, Şeyda CANBOLAT ${ }^{1}$, Habib DAYIOGLU ${ }^{1}$, Nigar MERDAN ${ }^{1}$ Filiz AKIN $^{3}$ \\ ${ }^{1}$ Istanbul Commercial University, Faculty of Design and Engineering, Department of Fashion and Textile, Istanbul, Turkey \\ ${ }^{2}$ Marmara University, Faculty of Technology, Department of Textile Engineerin, Istanbul, Turkey \\ ${ }^{3}$ Abant Izzet Baysal University, Vocational High School, Bolu, Turkey
}

\begin{abstract}
In this investigation, wool fabrics were dyed with the natural dyes extracted from blueberry Vaccinıum Corymbosum L. via conventional, ultrasonic and microwave method. Before the dyeing process, some of the samples were applied oxygen plasma pre-treatment; the other sample was mordanted with aluminium potassium sulphate. The dyeing methods were evaluated in terms of color and fastness properties. The fastness results demonstrated that the mordanting caused to increase in the fastness properties. The results of measurements of color strength demonstrate that the samples with the best color strength were obtained in accordance with conventional and ultrasonic dyeing methods.
\end{abstract}

Keywords: Blueberry (Vaccinium Corymbosum L.), ultrasonic, microwave, plasma treatment, wool fabric.

\section{INTRODUCTION}

Fabrics have been dyed with synthetic and natural based dyes for many centuries. Both of natural and synthetic dyes have an advantages and disadvantages. Synthetic dyes are widely used due to their better colour fastness, low prices, repeatability and wide range of bright shades specifications [10]. However, synthetics dyes cause serious health hazards, overbalancing the ecological life problems, as a matter of fact some synthetic textile dyes have been utilized mutagenity, genotoxicity, toxicity [7-9]. For these reasons interest of natural dyes have been increasing recently. But natural dyes cannot be produced as far as synthetic dyes and repeatability of same colour hue cannot be easily [19]. Natural dyes are produced from the plant and insect shell such as Buckthorn berry, Isatis tinctoria, Dactylopius coccus, Laccifer lacca, Reseda lutea L.,Antehemis tinctoria, Verbascum sp. Etc[8,9]. Natural dyes are divided into two categories: substantive and adjective. Substantive dyes are chemically fixed to the textile material without any additives such as indigo. Adjective dyes need some additives to provide colour, wash, and light fastness [1]. Textile industry has investigated new technologies to solve textile dyeing problems which are water pollution, usage a lot of dye and time consuming because of insufficient conventional systems [15-21]. New
Textile technologies are plasma, ultrasonic and microwave systems. Textile plasma application is pre-treatment and it is used to improve hydrophobicity, hydrophilicity, dye exhaustion, adhesion, antifelting and antibacterial properties of textile materials. In addition to these advantages plasma system is environmental friendly, dry technique in connection with low water and chemical consumption [14,16-18].The second alternative system is ultrasonic system. Ultrasonic system provides dye efficiency increasing under lower temperature and lower chemical concentration as well as ultrasonic textile application has shorter reaction cycle, less expensive, ecological features and ultrasonic system provides better colourfastness and light fastness when compared to the conventional textile applications $[3,5,6,12,13]$. Another new textile application is microwave systems which are used to decrease the reaction cycle, energy consumption as well as dye efficiency increases after the microwave application [11-20]. In this study wool fabrics were dyed with the natural dyes extracted from Vaccinium Corymbosum L.via ultrasonic, microwave and conventional methods. Also some of the samples dyed via conventional method were treated oxygen plasma application, whereas others were mordanted with aluminium potassium sulphate prior to the dyeing process. Afterwards the colour and fastness features have been investigated with regard to dyeing method.

Corresponding Author: Mehmet KILINC, Tel: +90 (212) 51141 88, E-mail: mkilinc@ticaret.edu.tr Submitted: 15 October 2014, Revised: 04 March 2015, Accepted: 01 July 2015 


\section{MATERIAL AND METHODS}

\subsection{Material}

In this study, $100 \%$ wool nonwoven which was $110 \mathrm{~g} / \mathrm{m}^{2}$ was used. For dyeing process, these materials are used as 3 gram weight.

\subsection{Methods}

\subsubsection{Plasma treatment}

The plasma treatment of wool was performed with oxygen gas in Diener vacuum plasma. The fabric sample was placed onto the anode and then the pressure of the chamber is adjusted at 0.3 mbar. The plasma treatment was performed with low frequency, at $40 \mathrm{kHz}$, and the duration of treatment lasted 5 minutes.

\subsubsection{The Mordanting process}

The preparation of the mordent solution; 10 grams potassium alum sulphate was dissolved in $1000 \mathrm{~mL}$ pure water. Afterword wool fabrics were treated with the solution for an hour at the boiling temperature. After the solution cooled down at the room temperature, the fabrics were taken out of the solution and squeezed.

\subsubsection{Dyeing process}

In this study, the samples were dyed with the blueberry extracts via conventional, ultrasound and microwave method. In all methods, the ratio of liquor was 1:50. In the conventional method, the samples were dyed at the boiling temperature for an hour. Then the samples were rinsed with cold water, hot water, and cold water, respectively. In the ultrasound method, the dying process was carried out with Maxwell Ultrasound Dyeing device at $70{ }^{\circ} \mathrm{C}$ for 15 minutes and the samples were exposed to $20 \mathrm{kHz}$ ultrasonic power. Then the samples were rinsed with cold water, hot water, and cold water, respectively. Microwave energy method with a mark type of machine was applied at a frequency of $2.45 \mathrm{GHz}$. The microwave oven had a maximal power of $800 \mathrm{~W}$ with six discrete settings. The fabric specimens were immersed to cooled dyestuff solution, and dyed in microwave oven at middle-high level for 3 minutes. After the dyeing process, the temperature of liquor was $40^{\circ} \mathrm{C}$.

\subsubsection{Evaluation of the colours obtained at the dying process}

Colour measurements of the samples were performed in the colour measuring device of Gretaq Macbeth - Colour Eye 2180UV. All the samples were measured from ten different regions of them and the average curves of wavelength-\%reflectance were obtained via calculation of the arithmetic mean of the reflectance values obtained at the every wavelength. The calculations were performed with respect to D65 light source and 10o standard observer. At the measurements the sample which was not mordanted was accepted as standard and the samples mordanted were compared in terms of the colours. The calorimetric values were measured according to the CIELAB system and the equation 1 was used to determine total colour differences [2].

$\Delta E^{-}=\sqrt{\left(\Delta L^{-}\right)^{5}+\left(\Delta a^{-}\right)^{5}+\left(\Delta b^{-}\right)^{5}}$

Where $\Delta \mathrm{E}^{*}$ refers to the total colour differences. In commercial regards, if $\Delta \mathrm{E}^{*}<1$, the value of colour differences could be accepted in general. The negative value of $\Delta \mathrm{L}^{*}$ result in that the colour of the samples compared is darker than that of the standard whereas the positive value of $\Delta \mathrm{L}^{*}$ results in that the colour of the samples compared is lighter than that of the standard. In the same way, the positive value of $\Delta \mathrm{a}^{*}$ results in surplus of the red nuance whereas the negative value of $\Delta \mathrm{a}^{*}$ results in surplus of the green nuance. The positive value of $\Delta b^{*}$ means that the yellow nuance is much whereas the negative value of $\Delta \mathrm{b}^{*}$ means that the blue nuance is much.

\subsubsection{Colour fastness}

The light and washing fastness of the samples coloured were tested according to the standard ISO105-C06 and ISO105-B02. The washing fastnesses of the samples were performed by using the washing fastness equipment (Gyrowash/James H.HealCo.Ltd.). Then the results were evaluated with the gray scale. The light fastness of the samples was performed by using the light fastness equipment with the blue scale (James H. Heal). In the assessment of the washing fastness performed according to the scale of 1 to 5 , " 5 " corresponds to the best value.

\section{RESULTS}

\subsection{Measurements of Colour}

The samples containing wool fabric was categorized into five groups in order to dye via conventional, ultrasonic and microwave methods. The first group of samples dyed with the blueberry extracts via conventional method was accepted as standard for colour measurement. The second group of samples mordanted with potassium aluminium sulphate was dyed with the blueberry extracts via conventional 
method. The third group of samples treated with oxygen plasma treatment was dyed with the blueberry extracts via conventional method. The fourth and fifth group of samples were dyed with the blueberry extracts via ultrasonic and microwave method, respectively.

$\Delta \mathrm{L}^{*} \quad$ (brightness-thickness), $\quad \Delta \mathrm{a}^{*}($ redness-greenness), $\Delta \mathrm{b}^{*}$ (yellowness-blueness) and $\Delta \mathrm{C}^{*}$ (saturation) values of the samples are shown in Figure 1.

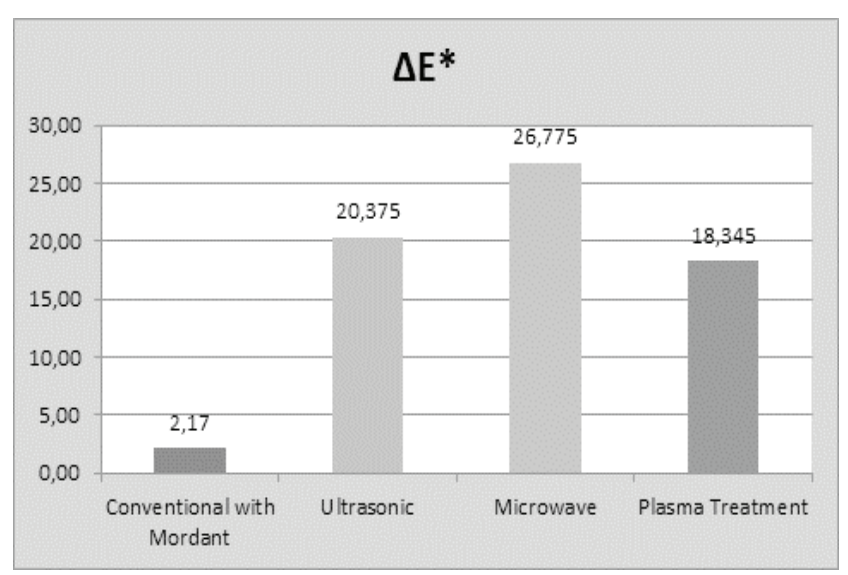

(a)

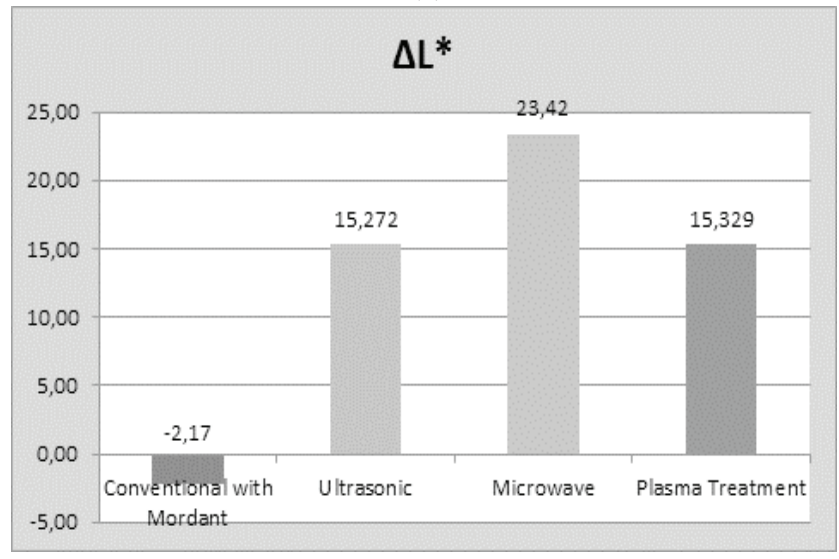

(b)

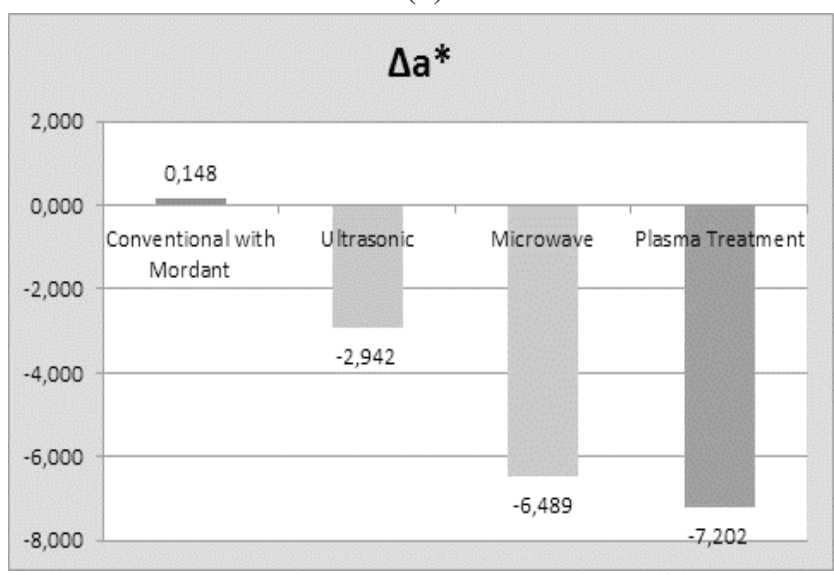

(c)

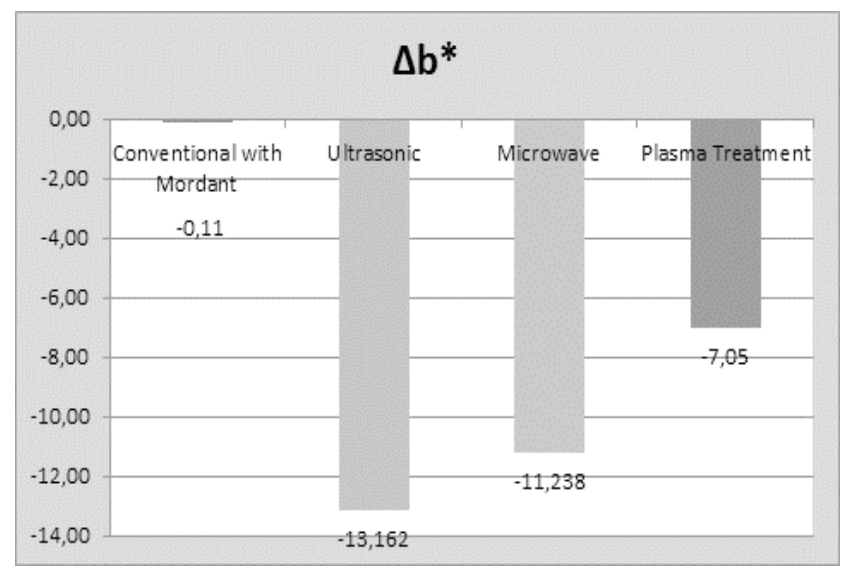

(d)

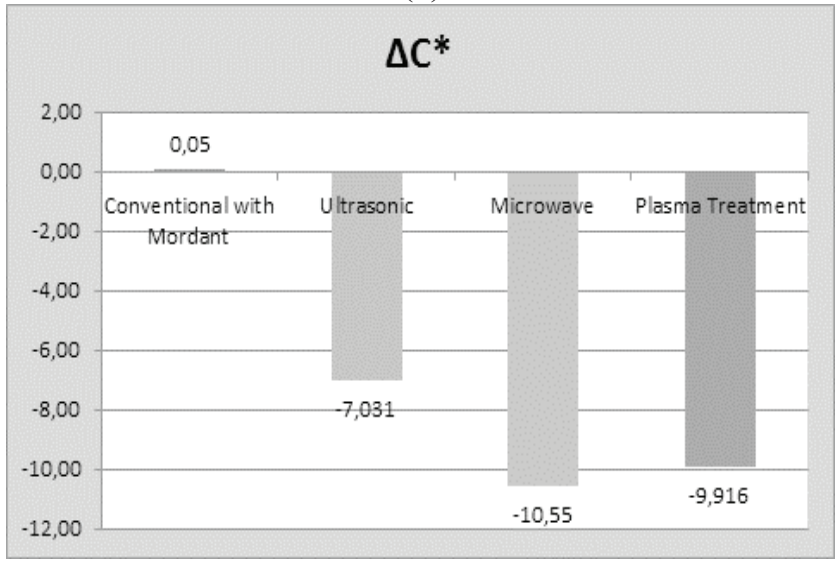

(e)

Figure 1. The colour measurement values of the wool samples

In the graphics, whereas the colour of the sample mordanted with potassium alum sulphate and dyed via conventional method, respectively, is darker than the standard sample, the other colours of the samples dyed via ultrasonic, microwave method, treated with plasma pre-treatment and dyed via conventional method are lighter than the standard sample. Potassium alum sulphate resulted in increasing quantity of the bonds between fibres and dyes. Also oxygen plasma pretreatment yielded better results in terms of increasing number of functional groups on the fibre, which, resulted in increasing quantities of the bonds between fibres and dyes. The colour of the sample treated with plasma pre-treatment and dyed via conventional method, respectively, is darker than the colour of the samples dyed via ultrasonic and microwave method. According to $\Delta \mathrm{a}^{*}$ values, while the wool sample mordanted with potassium aluminium sulphate and dyed via conventional method, respectively, involves much red nuance, the other 
wool samples have much green nuance. Also according to $\Delta \mathrm{b}^{*}$ values, blue nuance is dominant in all of the samples. The investigation of the Chroma values of samples demonstrates that while the Chroma value of the sample mordanted with potassium aluminium sulphate and dyed via conventional method, respectively, is high, the Chroma values of other samples are low. Finally the colour differences between the standard sample and the other samples dyed with different methods could not be accepted.

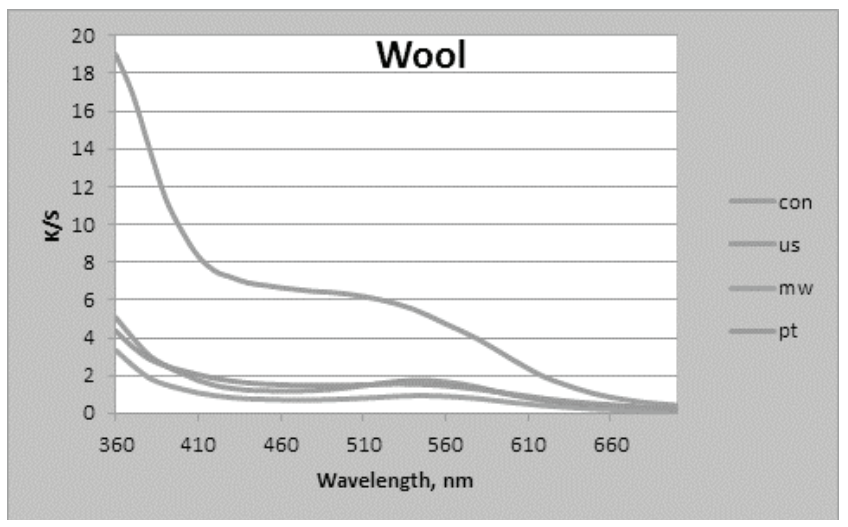

Figure 2. K/S values of wool samples

According to the graphics of the K/S values of the dyeing calculated with Kubelka-Munk Equation, the K/S values and, correspondingly, the colouring power in the blueberry extract along with the samples to which conventional, ultrasonic, microwave and plasma energy had been applied prior to dyeing process have been found higher in wool samples via conventional method (Figure 2).

\subsection{Results of Washing Fastness and Light Fastness}

Table 2. The washing fastness of wool fabrics

\begin{tabular}{|c|c|c|c|c|c|c|c|c|}
\hline \multicolumn{7}{|c|}{ Washing Fastness (Wool) } & Light \\
\hline $\begin{array}{c}\text { Processes } \\
\text { Plasma } \\
\text { Application } \\
\text { change }\end{array}$ & 1 & 5 & 5 & 5 & 5 & 5 & 5 & 3 \\
\hline $\begin{array}{c}\text { Microwave } \\
\text { Dyeing }\end{array}$ & 1 & 5 & 5 & 5 & 5 & 5 & 5 & $3 / 4$ \\
\hline $\begin{array}{c}\text { Ultrasound } \\
\text { Dyeing } \\
\text { without } \\
\text { Mordent agent }\end{array}$ & 1 & 5 & 5 & 5 & 5 & 5 & 5 & $2 / 3$ \\
\hline $\begin{array}{c}\text { Conventional } \\
\text { Dyeing } \\
\text { without } \\
\text { Mordent agent }\end{array}$ & 3 & 5 & 5 & 5 & 5 & 5 & 5 & 2 \\
\hline $\begin{array}{c}\text { Conventional } \\
\text { Dyeing with } \\
\text { Mordent agent }\end{array}$ & 2 & 5 & 5 & 5 & 5 & 5 & 5 & $2 / 3$ \\
\hline
\end{tabular}

As shown in Table 2, values of colour change with respect to the reference samples of, wool materials are quite low. In this regard, it is illustrated that these processes do not have much effect on the colour change in terms of washing fastness, which, instead, is mainly related to the mordents used.

According to the dye extracted from blueberry and the staining values of the samples on the multifibre test sample out of the samples dyed after which were applied conventional, ultrasonic and microwave energy and plasma, it has been surveyed that, in general, there are not a lot of differences among the staining values in all of the components on the sample fabric and that, staining is rare.

In a similar way, the processes have been demonstrated to have little effect on the staining fastness of the dyeing too. The washing process after dyeing is at least as significant as dyeing. The effectiveness of the washings at the end of process has itself much effect on the washing fastness.

Microwave applied wool has got the best light fastness. Plasma applied wool has got the moderate light fastness. Light fastness of wool increase related with the range of system wavelength.

\section{CONCLUSIONS}

In this study, wool fabrics were dyed with the natural dyes extracted from blueberry via different dyeing methods. Samples were applied either plasma pre-treatment or mordanted with potassium alum sulphate. According to the results, the colours of the samples mordanted with potassium alum sulphate were darker than the colours of other samples. Also the values of colour differences of the cotton and silk fabrics were accepted. Finally, the dyeing methods did not effect to improve the staining fastness of samples. To conclude, it should be specified that plasma pre-treatment, ultrasonic and microwave methods provide an eco-friendly dyeing process for wool materials dyed with blueberry dyes. Plasma and Microwave applied wool has got better light fastness then the others. Microwave and plasma application increase the light fastness of wool fabric.

Likewise, it has been demonstrated that the processes are not much effective on the staining fastness of the dyeing too. Pursuant to the washing fastness of the dyeing extracted from blueberry in terms of colour change, the desired values of colour changes could be achieved by using different mordents. 


\section{REFERENCES}

[1] Daniel M., Bhattacharya S.D., Arun, A. and Vinay R., (2006),".Natural Dyes: Scope and Challenges", Scientific Publishers, India.

[2] Fairchild, M.D.; Color Appearance Models, Addision Westley 2013

[3] Frederick JR. Ultrasonic engineering. London: John Wiley; 1965

[4] Kamel, M.M., Shishtawy, R.M., Youssef, B.M., Mashaly, H., (2006)," Ultrasonic Assisted Dyeing. IV. Dyeing of Cationised Cotton with Lac Natural Dye",Dye and Pigments, 73, 279-284

[5] Kamel M.,El-shishtawy R.M., Yussef B.M.,Mashaly H.,(2005), ’Ultrasonic assisted dyeing III. dyeing of wool with lac as natural dye",Dyes and Pigments,v.65,pp.103-110.

[6] Kamel M.M.,El-Zawahry M.M.,Ahmed N.S.E.,Abdelghaffar F., (2009),'Ultrasonic dyeing of cationized cotton fabric with natural dye.Part:1 Cationization of cotton using Solfix E", Ultrasonics Sonochemistry,v.16,pp.243-249.

[7] Kumaresan M., Palanisamy P.N.,Kumar P.E., (2012),"Application of eco-friendly natural dye obtained from Cordia sebestena on cotton using combination of mordants", Scholar Research Library,v.2,pp.32-38.

[8] Karadağ R.,'Natural Dyeing", (2007),T.C.Kültür ve Turizm Bakanlığı.

[9] Kumbasar E.P.A.,"Natural Dyes", (2011),Intech Open.

[10] Mirjalili M.,Nazarpoor K.,Karimi L.,(2011),'EcoFriendly dyeing of wool using natural dye from weld as co-partner with synthetic dye",Journal of Cleaner Production, ,v. 19,pp. 1045-1051.

[11] Nourmohammadian, F., Gholami, M.D., (2008),"An Investigation of Dyeability of Acrylic Fiber via
Microwave Irridiation",Prog.Color Colorants Coat., 1,57-63.

[12] Perincek, S., (2006) "An Investigation On The Applicability Of Ultrasound, Ultraviolet, Ozone And Combination Of These Technologies As A Pretreatment Process", Master of Science Thesis, Ege University,

[13] Perincek D.S., Duran K.,Körlü A.E.,Bahtiyari M.İ., , (2007)"Ultraviolet Technology",Tekstil ve Konfeksiyon,v.4,pp.219-223.

[14] Rauscher H., Perucca M., Buyle G., (2010), Plasma Technology for Hyperfunctional Surfaces: Food, Biomedical and Textile Applications, Woodhead Publishing Limited

[15] Saravanan P.,Chandramohan G.,Saivaraj S.,Deepa D., (2013),"Extraction and application of eco-friendly natural dye obtained from barks of Odina wodier.L on cotton Fabric", Scholar Research Library ,v.3,pp. 8085

[16] Shishoo R., (2007),"Plasma Technologies for Textile, Woodhead Publishing Limited

[17] Sparavigna A.,"Plasma treatment advantages for textiles", (2008), Cornell University Popular Physics.

[18] Sun D., Stylios G.K.,"Effect of low temperature plasma treatment on scouring and dyeing of natural fabrics", (2004), Textile Research Journal, v.74, pp.751-756.

[19] Tutak M., Benli H.," Investigation of dyeing properties of natural dyes obtained from some plants on wool ", (2008), BAÜ FBE Journal, v.10, pp.53-59.

[20] Xu, W., Yang, C., (2002), "Hydrolysis and Dyeing of Polyester Fabric Using Microwave Irridation ",Color. Technol., 118, 211-214.

[21] Vankar S.P., Rakhi S.,(2008),"Ecofriendly ultrasonic natural dyeing of cotton fabric with enzyme pretreatments", Desalination,230,pp.62-69. 